ARTIGO

Recebido em:

21/07/2016

Aceito em:

$12 / 08 / 2016$

\title{
Patentes universitárias brasileiras: perfil dos inventores e produção por área do conhecimento
}

\author{
Brazilian university patents: profile of inventors and \\ production per knowledge area
}

\author{
Adriana Stefani CATIVELLI \\ Mestre em Gestão de Unidades de Informação - UDESC - adrianacativelli@gmail.com \\ Elaine Rosangela de Oliveira LUCAS \\ Professora do Departamento de Biblioteconomia - UDESC - lanilucas@gmail.com
}

\section{Resumo:}

0 estudo caracteriza as invenções provenientes das patentes universitárias brasileiras quanto à autoria e área de assunto, com o propósito de identificar quais são os possíveis departamentos e áreas das instituições, que estão concentrando esforços ou possuem maior facilidade, em produzir e atingir a concessão de patentes no Brasil. Utilizou-se para o levantamento de dados acerca das universidades, a plataforma E-mec; a base de dados do Instituto Nacional de Propriedade Industrial (INPI) para as coletas de informações referentes às patentes; e a Classificação Internacional de Patentes (CIP) para determinar as áreas do conhecimento contempladas. Desta forma, foram analisadas a produção de patentes por região brasileira; as universidades com patentes concedidas; a quantidade de inventores por patente; o perfil dos principais inventores; e as patentes concedidas conforme a CIP. Os resultados indicam que as características das patentes concedidas às Universidades Públicas Brasileiras são provenientes das áreas de Química e Metalurgia, desenvolvidas por professores com formação em Química ou Engenharia Mecânica e pertencem na sua maioria à Universidade Estadual de Campinas (UNICAMP).

Palavras-chave: Patentes. Universidade Pública. Inovação Tecnológica.

\begin{abstract}
:
The study characterizes the inventions of patents of Brazilian universities concerning authorship and subject area to identify the institutions' possible departments and areas that concentrate efforts on or are more easily able to produce and achieve the patent grants in Brazil. For the data collection of the universities, we used the E-mec platform; the database of the National Institute of Industrial Property (INPI) for the collection of information concerning patents; and the International Patent Classification (IPC) to determine the covered knowledge areas. Thus, we analyzed the production of patents by Brazilian region; the universities with patents granted; the number of inventors per patent; the profile of the main inventors; and the patents granted according to the IPC. The results indicate that the characteristics of the patents granted to Brazilian Public Universities belong predominantly to the areas of Chemistry and Metallurgy. They are developed by professors with graduation in Chemistry or Mechanical Engineering and most of them belong to the State University of Campinas.
\end{abstract}

Keywords: Patents. Public university. Technological innovation.

v. 21, n. 47,2016 p. 67-81

ISSN 1518-2924
Esta obra está licenciada sob uma Licença Creative Commons. 


\section{INTRODUÇÃO}

O conhecimento produzido nas universidades que pode resultar em processos e produtos comercializáveis tem se tornado foco de debate nas universidades. A publicação desse tipo de conhecimento que protege tanto a descrição do conhecimento descoberto como a aplicação do mesmo é a patente. Esta por sua vez, garante ao titular a exploração exclusiva do objeto concebido, excluindo terceiros de utilizarem por um período de tempo delimitado por lei, sem a sua permissão, o conhecimento contido na patente.

Ao contrário do artigo científico, em que os autores figuram em papel de destaque e a instituição em papel secundário, com a patente acontece o contrário, o protagonismo fica por conta da instituição a que pertencem os autores.

No documento de patente existem dois papéis pré-estabelecidos para os envolvidos. 0 'titular' que também pode ser chamado de requerente ou depositante, este é o proprietário da patente, que pode ser pessoa física ou jurídica. A outra responsabilidade é designada ao 'inventor', também conhecido como autor ou criador, sendo a pessoa física que encontrou a solução do problema por meio do ato criativo.

No Brasil, segundo relatório da Derwent Innovations Index ${ }^{1}$, as universidades públicas estão entre as maiores produtoras de patente. Este fenômeno deve-se ao fato de que

Os gastos brasileiros em P\&D vinculam-se majoritariamente às grandes empresas estatais em articulação com os institutos de pesquisa nacionais. A fragilidade da dimensão empresarial da política tecnológica brasileira tem causas diversas, mas principalmente está marcada pelo elevado grau de transnacionalização da economia brasileira e pela dinâmica do processo de substituição das importações. [...] Estes dados apontam para um distanciamento entre a ciência local e as empresas brasileiras, pois poucas optam pelo desenvolvimento de conhecimento e agregação de valor em seus produtos e serviços ou o fazem pela via da importação ou transferência de tecnologia do exterior. (CASTRO; SOUZA, 2012, p. 126).

Demonstrando então, que as universidades ganham destaque no ranking da produção de patentes, em razão da fragilidade das empresas nacionais em investir no desenvolvimento de pesquisa e desenvolvimento (P\&D).

Quanto aos estudos sobre a produção de patentes realizados no Brasil, a análise sempre recaí sobre os pedidos de patentes devido ao grande delay na conquista da carta-patente. Tal medida se justifica, pois, estamos falando de inovações tecnológicas, que se tornam obsoletas em um curto período de tempo e a fim de identificar quais as últimas tendências das instituições e de assuntos a alternativa é o uso dos indicadores de solicitações de patentes.

Além da morosidade que ocorre entre a solicitação e a concessão da patente, muitos dos inventos registrados no Instituto Nacional de Propriedade Industrial (INPI) acabam por não atingirem a concessão, ou seja, essas invenções ficam desprotegidas para quem quiser fazer uso delas. Mas, e quanto as inovações tecnológicas que atingem a concessão? Quais são as áreas do conhecimento e inventores dessa produção?

Com a motivação de encontrar a resposta para estes questionamentos desenvolve-se a presente pesquisa com o intuito de caracterizar as invenções provenientes das patentes quanto a autoria e área de assunto. Para que seja possível identificar quais são os possíveis departamentos e áreas das instituições, que estão

1 Base de dados da Thomson Reuters Scientific com referências e resumos de mais de 11 milhões de patentes registradas. 
concentrando esforços ou possuem maior facilidade, em produzir e atingir a concessão das patentes.

\section{INOVAÇÃO, INVENÇÃO E TECNOLOGIA}

Na literatura, ao adentrar no tema patentes, as palavras inovação, invenção e tecnologia aparecem com frequência e por vezes são usadas como sinônimos. No entanto, faz-se necessário diferenciar os conceitos com o intuito de não causar confusão entre as palavras que possuem certa ligação, mas cada qual é imbuída de significado próprio e deve ser usada corretamente.

A palavra invenção pode ser definida "[...] como uma nova solução para um problema técnico específico, dentro de um determinado campo tecnológico." (WIPO, [2014]). Significa a ação de criar algo totalmente novo, no qual concentra-se esforços para a resolução de um problema que foi detectado.

Quanto a inovação, segundo o Manual de Oslo, configura-se na implementação "[...] de um produto (bem ou serviço) novo ou significativamente melhorado, ou um processo, ou um novo método de marketing, ou um novo método organizacional nas práticas de negócios, na organização do local de trabalho ou nas relações externas." (OCDE, 2005, p. 55).

De fato, esse é um significado amplo, e quando diz respeito às patentes, está referindo-se à inovação em produtos (desenvolvimento de novos produtos inexistentes ou então a melhoria no funcionamento daqueles já existentes) e processos (desenvolvimento ou aprimoramento nos processos de fabricação ou distribuição de bens ou prestação de serviços).

A inovação pode ser classificada em três graus de novidade, conforme o ponto de vista (OCDE, 2005):

a) Da empresa - quando a mudança é implementada no âmbito da empresa, no entanto já existe em outros ambientes;

b) Do mercado - quando a empresa é a primeira a introduzir a inovação no mercado regional ou setorial;

c) Do mundo - quando a inovação é introduzida pela primeira vez em todos os mercados e indústrias, tanto no âmbito nacional como internacional.

Verifica-se que a diferença entre a invenção e a inovação reside nos termos 'conceber' e 'usar', respectivamente (ROMAN; FUETT JÚNIOR, 1983 apud JUNG, 2009). Dessa forma, a invenção é algo que se concebe quando se concentram esforços a fim de atingir um determinado objetivo e a inovação compreende seu uso pela primeira vez no âmbito local, regional ou global.

No que se refere à tecnologia, a definição ganha significados distintos conforme a ótica adotada. Quando mencionada, é impossível não pensar em tecnologia do ponto de vista instrumentalista, com equipamentos sofisticados de última geração. No entanto, a tecnologia é mais que isso, ela exige

[...] um profundo conhecimento do porquê e do como seus objetivos são alcançados, se constituindo em um conjunto de atividades humanas associadas a um sistema de símbolos, instrumentos e máquinas, e assim, visa a construção de obras e a fabricação de produtos, segundo teorias, métodos e processos da ciência moderna. (VERASZTO et al., 2008, p. 78).

Após pesquisa bibliográfica com característica histórica, Veraszto e colaboradores chegam a conclusão de que a tecnologia "[...] é um conjunto de saberes inerentes ao desenvolvimento e concepção dos instrumentos (artefatos, sistemas, processos e ambientes) criados pelo homem através da história para satisfazer suas necessidades e requerimentos pessoais e coletivos." (VERASZTO, et 
al., 2008, p. 78). Ou seja, constitui-se como algo volátil, que desencadeia processos e fluxos feitos para sofrer mudanças constantes, visando atender às necessidades humanas.

Para Silva (2002), a tecnologia é um sistema composto de equipamentos, programas, pessoas, processos, organização e finalidade de propósito, que visa satisfazer os anseios da sociedade. Ela encontra-se embutida nos processos e operações dentro de um sistema produtivo e, no final deste, incorporada ao produto final na função de manufatura.

As definições construídas por Silva e Veraszto e outros abordam o significado abrangente da tecnologia, presente em todo o ambiente, como se ela estivesse impregnada nas pessoas e no local que vai conceber o objeto desejado. Afinal, a tecnologia constitui-se numa espécie de degraus do conhecimento, em que o homem utiliza metodologias e utensílios que estão em constante transformação, com a incessante busca do modificar.

Quando se traz a tecnologia para o contexto da inovação, tem-se o termo "inovação tecnológica", que diz respeito à

[...] concepção de novo produto ou processo de fabricação, bem como a agregação de novas funcionalidades ou características ao produto ou processo que implique melhorias incrementais e efetivo ganho de qualidade ou produtividade, resultando maior competitividade no mercado/setor de atuação. (BRASIL, 2011).

Constata-se que as três palavras - inovação, invenção e tecnologia encontram-se imbricadas, sendo que a patente carrega consigo os três significados das palavras citadas, que segundo o artigo 8 da lei 9.279, só é "[...] patenteável a invenção que atenda aos requisitos de novidade, atividade inventiva e aplicação industrial." (BRASIL, 1996). Portanto, para ser considerada patente, o processo ou produto, deve tratar-se de uma invenção que será produzido com o uso de tecnologias, provocando a inovação no cotidiano daquele ambiente onde será utilizada e que se constituirá em uma nova tecnologia que atenderá as demandas da realidade onde estará inserida.

\section{OPÇÕES METODOLOGICAS}

A captura dos nomes das Universidades Públicas Brasileiras (UPBs) foi realizada na Plataforma E-mec ${ }^{2}$. Quanto a coleta dos dados de titularidade, inventor e área do conhecimento das patentes, conforme a Classificação Internacional de Patentes (CIP), elegeu-se a base de dados do INPI.

0 período analisado abrange desde a primeira patente concedida, catalogada na base de dados do INPI - que data de 1979 - até janeiro de 2016, data da coleta de dados.

Os dados coletados foram dispostos e organizados em planilhas do software Microsoft Office Excel®, para em seguida gerar gráficos no software Tableau Public ${ }^{\circledR}$, utilizado a fim de representar e desenhar de forma adequada o volume de dados coletados.

\section{PRODUÇÃO DE PATENTES POR REGIÃO DO BRASIL}

$\mathrm{Na}$ plataforma E-mec foram coletados os nomes de 106 universidades públicas, para em seguida realizar o levantamento dos dados das patentes

2 Disponível em: http://emec.mec.gov.br/

3 Software Tableau Public. Disponível em: https://public.tableau.com/s/download 
concedidas na base do INPI. Identificou-se o total de 29 universidades com patente concedida e juntas, elas produziram 538 patentes.

A região Sudeste é quem lidera as estatísticas das UPBs, com $60,63 \%$ das patentes solicitadas e $88,1 \%$ das patentes concedidas, concentrando no estado de São Paulo os maiores índices de produção industrial do país. Somente este estado é responsável por $34,9 \%$ das solicitações e $65,2 \%$ das concessões de patentes em relação as demais UPBs.

A segunda colocação é da região Sul, com 20,13\% de solicitações e 7,25\% de concessões e o estado que apresenta os números mais significativos em atividades patentarias é o Paraná.

Em terceiro lugar, quanto as patentes concedidas, aparece a região CentroOeste, com 4,07\% de solicitações e 2,23\% de concessões, sendo o Distrito Federal o estado que se destaca, mesmo apresentando somente uma UPB avaliada.

Em quarto lugar, está a região Nordeste, apresentando 13,43\% e 2,04\%, com destaque para Pernambuco em números de registros.

E o último lugar ficou com a região Norte, com 1,74\% das solicitações e $0,38 \%$ das concessões das patentes das UPBs.

Na tabela 1 apresenta-se a quantidade de patentes solicitadas e as patentes concedidas às UPBs por estado brasileiro.

Tabela 1: Quantidade de patentes solicitadas e concedidas às UPBs por estado.

\begin{tabular}{|c|c|c|c|c|c|c|c|c|}
\hline \multirow[b]{2}{*}{ Estados Brasileiros } & \multirow[b]{2}{*}{ UPBs } & \multirow[b]{2}{*}{$\begin{array}{c}\text { Qtde. de } \\
\text { Patentes } \\
\text { solicitadas }\end{array}$} & \multirow[b]{2}{*}{$(\%)$} & \multicolumn{4}{|c|}{ Patentes Concedidas } & \multirow[b]{2}{*}{$(\%)$} \\
\hline & & & & PI* & $\mathbf{M U}^{* *}$ & $\mathrm{C}^{* * *}$ & $(=)$ & \\
\hline Acre & 1 & 3 & 0,04 & - & - & - & - & - \\
\hline Amapá & 2 & - & - & - & - & - & - & - \\
\hline Amazonas & 2 & 14 & 0,2 & - & - & - & - & - \\
\hline Pará & 5 & 104 & 1,47 & 2 & - & - & 2 & 0,38 \\
\hline Rondônia & 1 & - & - & - & - & - & - & - \\
\hline Roraima & 2 & - & - & - & - & - & - & - \\
\hline Tocantins & 2 & 2 & 0,03 & - & - & - & - & - \\
\hline Região Norte & 15 & 123 & 1,74 & 2 & 0 & 0 & 2 & 0,38 \\
\hline Alagoas & 3 & 34 & 0,48 & - & - & - & - & - \\
\hline Bahia & 8 & 169 & 2,38 & 1 & - & - & 1 & 0,18 \\
\hline Ceará & 6 & 135 & 1,9 & - & - & - & - & - \\
\hline Maranhão & 3 & 44 & 0,62 & - & - & - & - & - \\
\hline Paraíba & 3 & 106 & 1,49 & 1 & - & - & 1 & 0,18 \\
\hline Pernambuco & 4 & 192 & 2,71 & 3 & - & - & 3 & 0,57 \\
\hline Piauí & 2 & 58 & 0,82 & - & - & - & - & - \\
\hline Rio Grande do Norte & 3 & 105 & 1,48 & 1 & - & - & 1 & 0,18 \\
\hline Sergipe & 1 & 110 & 1,55 & 5 & - & - & 5 & 0,93 \\
\hline Região Nordeste & 33 & 953 & 13,4 & 11 & 0 & 0 & 11 & 2,04 \\
\hline Distrito Federal & 1 & 144 & 2,03 & 10 & 1 & - & 11 & 2,04 \\
\hline Goiás & 2 & 82 & 1,15 & 1 & - & - & 1 & 0,18 \\
\hline Mato Grosso & 2 & 34 & 0,48 & - & - & - & - & - \\
\hline Mato Grosso do Sul & 3 & 29 & 0,41 & - & - & - & - & - \\
\hline Região Centro-Oeste & 8 & 289 & 4,07 & 11 & 1 & 0 & 12 & 2,23 \\
\hline Espírito Santo & 1 & 33 & 0,46 & - & - & - & - & - \\
\hline Minas Gerais & 13 & 1264 & 17,8 & 65 & 17 & 1 & 83 & 15,43 \\
\hline Rio de Janeiro & 7 & 527 & 7,43 & 36 & 4 & - & 40 & 7,43 \\
\hline São Paulo & 8 & 2477 & 34,9 & 321 & 30 & - & 351 & 65,24 \\
\hline Região Sudeste & 29 & 4301 & 60,6 & 422 & 51 & 1 & 474 & 88,1 \\
\hline Paraná & 11 & 738 & 10,4 & 16 & 3 & - & 19 & 3,53 \\
\hline Santa Catarina & 3 & 165 & 2,32 & 6 & - & - & 6 & 1,12 \\
\hline Rio Grande do Sul & 7 & 525 & 7,4 & 12 & 2 & - & 14 & 2,6 \\
\hline Região Sul & 21 & 1428 & 20,1 & 34 & 5 & 0 & 39 & 7,25 \\
\hline TOTAL GERAL & 106 & 7094 & 100 & 480 & 57 & 1 & 538 & 100 \\
\hline
\end{tabular}

Fonte: Dados da pesquisa. Coleta em janeiro de 2016.

Legenda: PI* Patente de Invenção; MU** Modelo de Utilidade; C***Certificado de Adição.

O Sudeste do país consegue atingir esse elevado número de patentes perante as outras regiões devido a uma série de fatores. Dentre eles podemos citar: 
concentra mais de $40 \%$ da população brasileira, é a região com a maior densidade demográfica (87 habitantes por $\mathrm{km}^{2}$ ), detém o mais alto índice de urbanização (92,95\%), abriga as duas metrópoles mais importantes do país (São Paulo e Rio de Janeiro) e tem a economia mais desenvolvida e industrializada do Brasil, concentrando mais da metade da produção (IBGE, 2010).

Além disso, a região Sudeste é responsável por concentrar o maior número de publicações acadêmicas do país, esse fator "[...] decorre diretamente da maior concentração de pesquisadores, investimentos públicos e instituições científicas e tecnológicas que se localizam naquela região." (OLIVEIRA, 2011, p. 46).

Em relação à região Norte, que apresentou a menor quantidade de depósitos e concessões, nota-se que o estado do Pará obteve destaque na região, com 104 solicitações e duas patentes concedidas. Tal fato causa estranheza, pois é o estado do Amazonas, também localizado da região Norte, que detém "[...] a Zona Franca de Manaus, e possui um expressivo número de empresas de alta e de média alta tecnologia - que demandam recursos humanos qualificados" (INPI, 2007, p. 15), e ainda assim indicou apenas 14 patentes depositadas e nenhuma concedida.

\section{UNIVERSIDADES COM PATENTES CONCEDIDAS}

A Universidade Estadual de Campinas (UNICAMP) e a Universidade de São Paulo (USP) foram as duas universidades que concentraram mais da metade da produção de patentes das UPBs com $57,2 \%$, veja na tabela 2 . Este resultado não é por acaso, pois as duas instituições já na década de 1980, demonstravam a preocupação em relação à propriedade intelectual, sendo as primeiras a estabelecerem algum tipo de regulamentação interna sobre o tema (OLIVERIA, 2011).

Tabela 2: Universidades com patentes concedidas

\begin{tabular}{|c|c|c|c|}
\hline Ordem & Universidades & Patentes Concedidas & $(\%)$ \\
\hline $\mathbf{1}^{\mathbf{a}}$ & UNICAMP (SP) & 170 & 31,6 \\
\hline $2^{\underline{a}}$ & USP (SP) & 138 & 25,6 \\
\hline $3^{\underline{a}}$ & UFMG (MG) & 52 & 9,7 \\
\hline $4^{\underline{a}}$ & UFRJ (RJ) & 39 & 7,2 \\
\hline $5^{\mathbf{a}}$ & UFSCar (SP) & 27 & 5 \\
\hline $6^{-\mathbf{a}}$ & UFV (MG) & 21 & 3,9 \\
\hline $7 \underline{\mathbf{a}}$ & UNESP (SP) & 13 & 2,4 \\
\hline $8^{\mathbf{a}}$ & UFRGS (RS) & 12 & 2,2 \\
\hline \multirow[t]{2}{*}{ 9a } & UNB (DF) & 11 & 2 \\
\hline & UFOP (MG) & 6 & 1,1 \\
\hline \multirow[t]{2}{*}{$10^{\mathbf{a}}$} & UFSC (SC) & 6 & 1,1 \\
\hline & UEM (PR) & 5 & 0,9 \\
\hline \multirow[t]{3}{*}{$11^{\mathbf{a}}$} & UFS (SE) & 5 & 0,9 \\
\hline & UTFPR (PR) & 5 & 0,9 \\
\hline & UFPR (PR) & 4 & 0,7 \\
\hline \multirow[t]{3}{*}{$12^{\mathrm{a}}$} & UFU (MG) & 4 & 0,7 \\
\hline & UFPE (PE) & 3 & 0,5 \\
\hline & UNIFESP (SP) & 3 & 0,5 \\
\hline $13^{\mathbf{a}}$ & UNIOESTE (PR) & 3 & 0,5 \\
\hline \multirow[t]{6}{*}{$14^{\mathrm{a}}$} & UFPA (PA) & 2 & 0,4 \\
\hline & UEPG (PR) & 1 & 0,2 \\
\hline & UESB (BA) & 1 & 0,2 \\
\hline & UFG (GO) & 1 & 0,2 \\
\hline & UFF (RJ) & 1 & 0,2 \\
\hline & UFPB (PB) & 1 & 0,2 \\
\hline \multirow[t]{4}{*}{$15^{\mathbf{a}}$} & UFPEL (RS) & 1 & 0,2 \\
\hline & UFRN (RN) & 1 & 0,2 \\
\hline & UFSM (RS) & 1 & 0,2 \\
\hline & UNICENTRO (PR) & 1 & 0,2 \\
\hline TOTAL & 29 UPBs & 538 & 100 \\
\hline
\end{tabular}

Fonte: Dados da pesquisa, 2016. 
Verifica-se que as sete primeiras colocadas fazem parte da região Sudeste, e quatro destas pertencem ao estado de São Paulo. Já o estado com maior número de universidades que patenteiam é o Paraná com seis.

Todas as cinco regiões brasileiras se fizeram presentes na tabela 2, no qual a região Sudeste (11) e Sul (10) apontam maior número de UPBs. A região que indicou o menor número de instituições foi a região Norte com apenas uma, a Universidade Federal do Pará (UFPA).

\section{QUANTIDADE DE INVENTORES POR PATENTE}

Com objetivo de averiguar a tendência dos inventores em desenvolver invenções, sozinhos ou em conjunto, analisou-se a quantidade de inventores por patente. 0 resultado dos dados coletados, são apresentados no Gráfico 1.

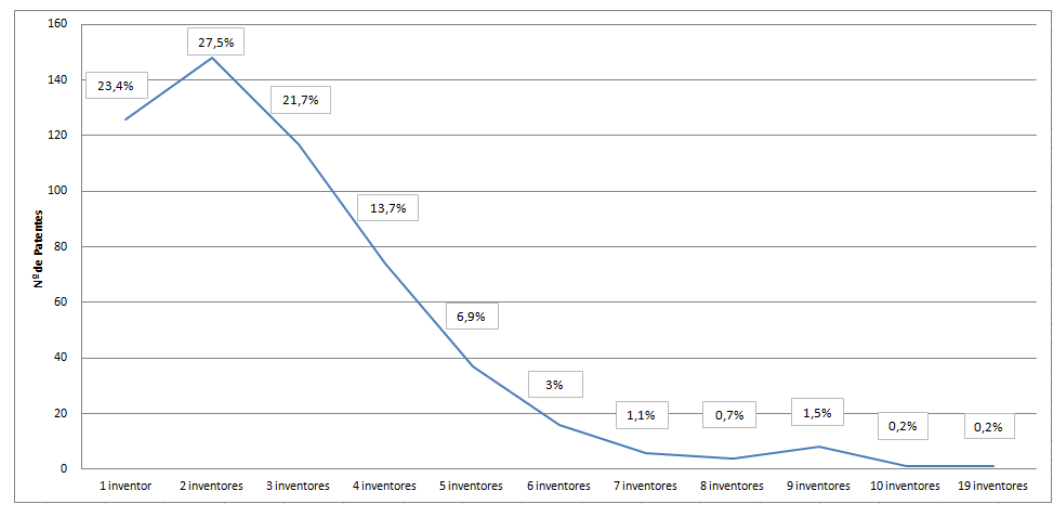

Gráfico 1: Quantidade de inventores por patente concedida

Fonte: Dados de pesquisa, 2016.

Os dados coletados mostram que os inventores das UPBs, em sua maioria, desenvolvem inventos em parceria com outro(s) inventor(es), pois das 538 patentes analisadas, 412 foram desenvolvidas por dois ou mais inventores. A preferência por realizar as invenções sozinhos foi representada por 126 patentes.

0 Gráfico 1 aponta que $72,6 \%$ das patentes obtiveram de um a três inventores. Esse indicador revela que o processo de invenção da patente é algo que requer foco e dedicação, no qual os inventores optam em produzir seus inventos sozinhos ou em grupos pequenos. Já grupos maiores podem prejudicar o andamento do trabalho, pois exigem que todos estejam alinhados e de acordo com as decisões tomadas. A partir da coautoria por quatro inventores, verifica-se que os números descressem gradualmente.

0 gráfico 1 também aponta que há uma rotulagem discrepante, na qual se apresentam 19 inventores. A invenção foi desenvolvida entre a UNICAMP e a Hytron (Indústria, Comércio e Assessoria Tecnológica em Energia e Gases Industriais Ltda), trata-se de um "reator de reforma autotérmica de etanol". Provavelmente, parte dos inventores possuem vínculo com a UNICAMP e a outra parte com a empresa Hytron e cada uma das parceiras desenvolveu um papel no processo de invenção do produto. No entanto, é importante observar que quando o número de inventores envolvidos em uma concessão de patente é elevado, surge a necessidade de definirse qual foi a função assumida por cada um na conquista.

Para isso, há uma proposta de modelo que vem sendo debatida no meio cientifico e trata-se de algo similar ao que acontece com as produções cinematográficas (filmes). Nestes tipos de produções, existe o diretor, o roteirista, o figurinista, entre outras funções que contribuem para a concretização do filme. Da 
mesma forma, esse formato poderia ser aplicado nas produções científicas, conforme o modelo abordado por Petroianu (2002).

Petroianu (2002, p. 60) defende que "[...] o mérito da autoria científica deve ser restrito aos participantes que tiveram uma colaboração intelectual ao trabalho realizado, aliada a uma contribuição efetiva para a pesquisa ser realizada e concluída." Baseado nisso, o autor construiu uma tabela, na qual cada participante da pesquisa identificaria qual ou quais foram suas funções desempenhadas e, a partir disso, realiza um somatório de pontos para verificar se tem direito à autoria ou não. 0 resultado mostrará ainda a "[...] ordem de entrada, os principais autores do trabalho e aqueles que devem merecer apenas agradecimento." (PETROIANU, 2002, p. 60).

\section{PERFIL DOS PRINCIPAIS INVENTORES}

Com o intuito de descobrir quais as características do perfil dos inventores das UPBs, foi realizado - na plataforma Lattes e base do INPI - um levantamento dos autores que atingiram acima de cinco patentes concedidas. Neste sentido, verificouse: área de formação, atividade desempenhada, quantidade de processos que constam em seu nome na base do INPI e qual a área da CIP dos respectivos processos.

Reuniu-se o total de 15 autores, identificados como aqueles que produziram o maior número de patentes no âmbito das UPBs. O inventor Kil Jin Park, foi o mais produtivo dentre eles. Acumulou o total de 12 patentes concedidas pelas UPBs e na base do INPI também constam 12 processos registrados em seu nome, acompanhe os dados no Quadro 1.

De acordo com as oito grandes áreas da CIP, Kil Jin Park efetuou invenções nas áreas de 'Necessidades Humanas', 'Química e Metalurgia' e 'Engenharia Mecânica; Iluminação; Aquecimento; Armas; Explosão'. 0 inventor é graduado e mestre em Engenharia de Alimentos pela UNICAMP; doutor em Engenharia Mecânica, também pela UNICAMP; assessor da Empresa Brasileira de Pesquisa Agropecuária (Embrapa) e professor titular da UNICAMP.

Nove dos 15 autores mais produtivos apresentaram titularidade majoritariamente à UNICAMP. 0 pesquisador foi vinculado à instituição a qual havia o maior número de patentes registrada como sendo de sua titularidade. Por exemplo, Kil Jin Park obteve uma patente concedida com a titularidade da Universidade Federal do Rio de Janeiro (UFRJ) e as demais na UNICAMP, portanto, o autor ficou vinculado à UNICAMP.

Ainda sobre o mesmo autor e abordagem da presente seção, identificou-se que Kil Jin Park desenvolveu parcerias com outros dois inventores presentes no Quadro 1. A citar: Felix Emilio Prado Cornejo e Regina Isabel Nogueira.

Os inventores citados são pesquisadores da empresa Embrapa e têm área de formação em comum com Kil Jil Park, Engenharia Mecânica e Engenharia de Alimentos, respectivamente. Como o autor - Kil Jil Park- exerce a função de docente na UNICAMP ademais da função de Assessor da Embrapa, constata-se que as parcerias de titularidade na produção das patentes, pode ser gerada a partir de inventores com vínculos múltiplos.

Também foi possível identificar outras parcerias entre os inventores mais produtivos. Rodnei Bertazzoli, que se encontra em segundo lugar em quantidade de patentes concedidas pelas UPBs, realizou parcerias com Marcos Spitzer e Marcos Roberto de Vasconcelos Lanza. Nos dois casos, averiguou-se que Rodnei Bertazzoli foi orientador de doutorado dos dois inventores mencionados, o que sugere que o tema de pesquisa defendido na tese dos autores pode ter resultado em inovações tecnológicas, gerando as patentes. 
Quadro 1: Formação e atuação dos inventores mais produtivos.

\begin{tabular}{|c|c|c|c|c|c|c|c|c|c|c|c|}
\hline \multirow[b]{2}{*}{ Inventores } & \multirow[b]{2}{*}{ Áreas de formação } & \multicolumn{2}{|c|}{ Patentes } & \multicolumn{8}{|c|}{ Áreas da ClP } \\
\hline & & UPB & INPI & $A$ & B & C & $\mathrm{D}$ & $\mathrm{E}$ & $\mathrm{F}$ & $G$ & $\mathrm{H}$ \\
\hline Kil Jin Park (UNICAMP) & $\begin{array}{l}\text { Engenharia de Alimentos/ } \\
\text { Engenharia Mecânica }\end{array}$ & 12 & 12 & 4 & - & 4 & - & - & 4 & - & - \\
\hline Rodnei Bertazzoli (UNICAMP) & Física/ Engenharia Mecânica & 11 & 28 & - & - & 27 & 1 & - & - & - & - \\
\hline Marcos Pinotti Barbosa (UFMG) & Engenharia Mecânica & 10 & 44 & 31 & 1 & - & - & 1 & 5 & 4 & 2 \\
\hline $\begin{array}{l}\text { Nelson Eduardo Duran Caballero } \\
\text { (UNICAMP) }\end{array}$ & Química & 9 & 45 & 13 & 3 & 25 & 2 & - & - & 2 & - \\
\hline $\begin{array}{l}\text { Felix Emilio Prado Cornejo } \\
\text { (UNICAMP) }\end{array}$ & $\begin{array}{l}\text { Engenharia Mecânica/ } \\
\text { Engenharia Agrícola }\end{array}$ & 7 & 13 & 8 & - & 2 & - & - & 3 & - & - \\
\hline Ines Joekes (UNICAMP) & Físico-química & 7 & 9 & 1 & - & 7 & - & - & - & 1 & - \\
\hline Edgar Dutra Zanotto (UFSCar) & Engenharia de Materiais/ Física & 6 & 13 & 2 & - & 8 & - & 1 & - & - & 2 \\
\hline Marcos Spitzer (UNICAMP) & Química/ Engenharia Mecânica & 5 & 7 & - & 1 & 6 & - & - & - & - & - \\
\hline Pedro Iris Paulin Filho (UFSCar) & $\begin{array}{l}\text { Engenharia de Materiais/ } \\
\text { Tecnologia Nuclear }\end{array}$ & 5 & 7 & - & - & 4 & - & - & - & - & 3 \\
\hline Carlos Chien-Ching Tu (USP) & $\begin{array}{c}\text { Engenharia Mecânica/ } \\
\text { Engenharia e Tecnologia } \\
\text { Nuclear }\end{array}$ & 5 & 8 & - & 2 & - & - & - & 2 & 4 & - \\
\hline $\begin{array}{l}\text { Elena Vitalievna Goussevskaia } \\
\text { (UFMG) }\end{array}$ & Química/ Catálise & 5 & 16 & - & 4 & 12 & - & - & - & - & - \\
\hline Ernesto Rafael Gonzalez (USP) & Físico-química/ Química & 5 & 2 & - & - & 2 & - & - & - & - & - \\
\hline Fernando Galembeck (UNICAMP) & Química & 5 & 28 & - & 1 & 22 & - & - & - & - & 3 \\
\hline $\begin{array}{l}\text { Marcos Roberto de Vasconcelos } \\
\text { Lanza (UNICAMP) }\end{array}$ & $\begin{array}{l}\text { Química/ Engenharia de } \\
\text { Materiais }\end{array}$ & 5 & 10 & - & - & 9 & - & - & - & 1 & - \\
\hline $\begin{array}{l}\text { Regina Isabel Nogueira } \\
\text { (UNICAMP) }\end{array}$ & $\begin{array}{l}\text { Engenharia de Alimentos/ } \\
\text { Engenharia Agrícola }\end{array}$ & 5 & 6 & 2 & - & 4 & - & - & - & - & - \\
\hline TOTAL & - & 101 & 248 & 61 & 12 & 132 & 3 & 2 & 14 & 12 & 10 \\
\hline
\end{tabular}

Fonte: Dados da pesquisa, 2016.

Observando o Quadro 1, percebe-se que grande parte da formação dos inventores é proveniente das áreas de Química e Engenharia Mecânica. É possível verificar que a formação nessas áreas propicia o desenvolvimento de novos processos e produtos, já que o profissional formado na área de Química

[...] estuda a matéria, sua composição e suas propriedades. Analisa substâncias e compostos, identifica suas características físicoquímicas, como dureza ou toxicidade. Investiga como os compostos reagem às variações de pressão e temperatura, entre outros fatores. Em indústrias químicas, pesquisa, por exemplo, novos materiais, supervisiona a produção e aplica testes de qualidade. Além disso, elabora projetos de instalações industriais e faz a manutenção de equipamentos. (GUIA DO ESTUDANTE, 2015).

Enquanto o profissional formado em Engenharia Mecânica

[...] desenvolve, projeta e supervisiona a produção de máquinas, equipamentos, veículos, sistemas de aquecimento e de refrigeração e ferramentas específicas da indústria mecânica. Seleciona e dimensiona a matéria-prima, providencia moldes das peças que serão fabricadas, cria protótipos e testa os produtos obtidos. Organiza sistemas de armazenagem, supervisiona processos e define normas e procedimentos de segurança na linha de produção. Controla a qualidade, acompanhando e analisando testes de resistência, calibrando e conferindo medidas. (GUIA DO ESTUDANTE, 2015). 
Os dois cursos citados são exemplos em áreas que têm um vasto campo de pesquisa aplicada, no qual utilizam o conhecimento adquirido na pesquisa básica em resoluções de problemas relacionados a aplicações concretas. 0 contato com laboratórios destinados a experiências e fabricação de protótipos durante a formação profissional também estimula a habilidade criativa do aluno, propiciando a criação de invenções futuras.

Outro motivo encontrado na literatura em relação à formação em Engenharia Mecânica, e que pode estar relacionado com a visão empreendedora conforme acontece na UNICAMP, apresenta a área como aquela que mais tem realizado projetos cooperativos com empresas privadas (DAGNINO; GOMES, 2003). É sabido que, quanto mais um curso de formação profissional traçar parcerias com instituições privadas, mais chances terá de se inserir no mercado empreendedor, que demanda novos produtos e processos.

0 quadro 1 também mostra que os inventores mais produtivos são em sua maioria professores universitários e/ou pesquisadores da Embrapa. Não foi possível identificar o vínculo institucional e função de um dos inventores.

O levantamento dos inventores na base do INPI teve o intuito de observar a quantidade total de processos registrados por inventor, no que se refere a solicitações de patentes, além de investigar se haviam registros de patentes fora de suas respectivas instituições universitárias de vínculo.

Os inventores que se sobressaem em quantidade de registros de patentes, independente do seu vínculo universitário, são: Nelson Eduardo Duran Caballero, com 45 processos, dos quais mais da metade refere-se à área 'Química e Metalurgia', todos com titularidade da UNICAMP e Marcos Pinotti Barbosa, que registrou 44 documentos, sendo a maioria na área 'Necessidades Humanas', e dos quais apenas uma das titularidades dos processos pertence à UNICAMP e o restante à Universidade Federal de Minas Gerais (UFMG).

Cabe salientar que os registros encontrados no INPI pertencentes aos inventores do Quadro 1, no que se refere às titularidades das solicitações e concessões de patentes, estão todas em nome das instituições as quais os inventores são vinculados.

\section{PATENTES CONCEDIDAS CONFORME A CLASSIFICAÇÃO INTERNACIONAL DE PATENTES (CIP)}

Nesta seção serão verificadas em quais áreas do conhecimento as UPBs conseguem proteger seus inventos. Para isso, coletou-se em cada documento de patente a primeira classificação recebida conforme a CIP e elaborou-se o Gráfico 3, presente na próxima página. 


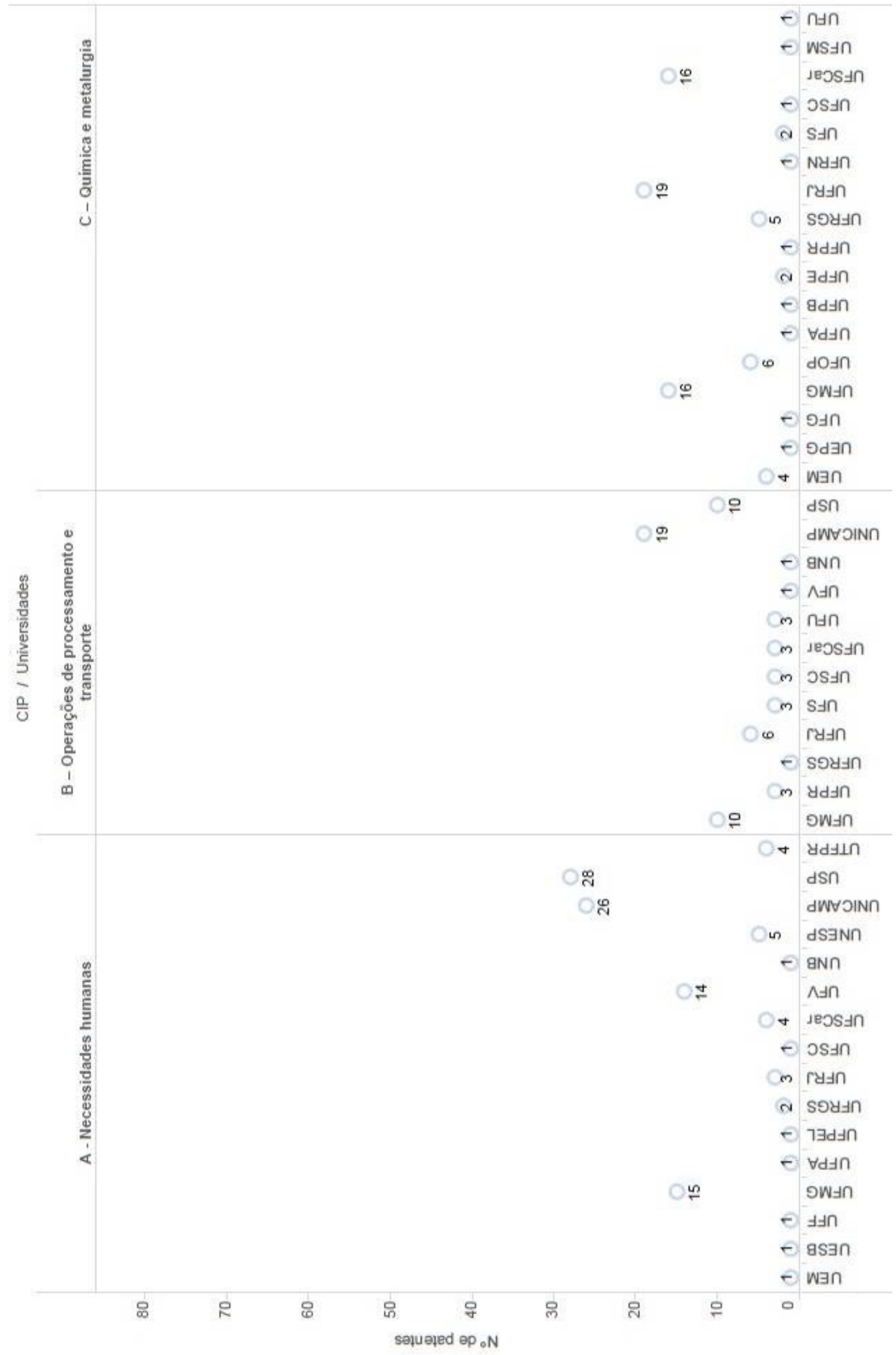




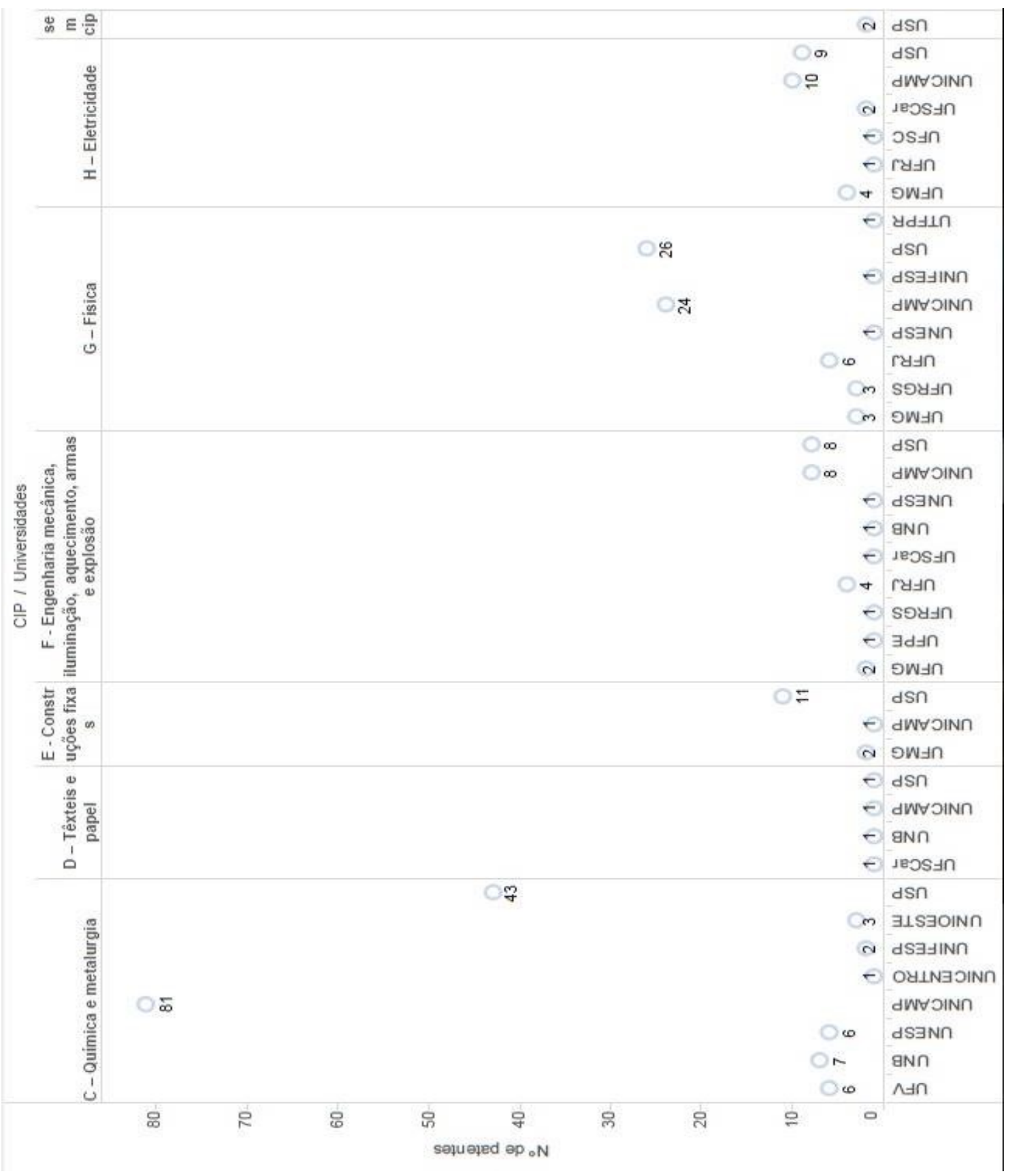

Gráfico 2: Patentes concedidas das UPBs conforme a CIP.

Fonte: Dados da pesquisa, 2016.

O Gráfico 2 revela que a área com o maior número de patentes concedidas é a área 'C - Química e Metalurgia', totalizando 42,4\%. Também foi a área em que grande parte das UPBs patentearam, pois, das 29 instituições que fizeram parte da população pesquisada, 25 apresentam-se na referida área.

A segunda área que mais obteve ocorrências foi a 'A - Necessidades Humanas', relativa a: agricultura; produtos alimentícios e tabaco; artigos pessoais ou domésticos; e saúde, salvamento e recreação. Essa concentrou 20,1\% das concessões, onde as UPBs que mais se destacaram na categoria foram: USP, UNICAMP, UFMG e Universidade Federal de Viçosa (UFV). 
A área 'G - Física', acumulou 12,1\% de patentes concedidas, na qual se destacaram UNICAMP e USP.

Em seguida, tem-se a área 'B - Operações de processamento; transporte' atingindo $11,7 \%$ de ocorrências. A UNICAMP, UFMG e USP foram as instituições que mais patentearam nessa área.

Empatadas, com 5\%, ficaram as áreas ' $\mathrm{F}$ - Engenharia mecânica, iluminação, aquecimento, armas, explosão' e 'H - Eletricidade'. As instituições que se destacaram foram UNICAMP e USP.

A área 'E - Construções fixas' concentrou 2,6\% das concessões, prevalecendo as patentes da USP.

Por fim está a área 'D - Têxteis e papel' com $0,7 \%$, na qual as UPBs que patentearam na área atingiram apenas uma concessão.

Nesse contexto, o INPI (2007) realizou um levantamento do perfil dos pedidos de patentes das universidades brasileiras no período de 2000 a 2004 . No qual os resultados mostraram que as áreas da CIP que concentraram os pedidos de patentes são semelhantes aos resultados que encontramos nesta pesquisa. A diferenciação está apenas na ordem das áreas, manifestada na classe $\mathrm{H}$ que aparece com mais frequência do que a área F, e não empatadas como no caso das concessões.

$\mathrm{Na}$ Tabela 3 é possível verificar os dados do levantamento do INPI e comparar com os números do Gráfico 2 apresentados anteriormente.

Tabela 3: Perfil dos depósitos segundo a CIP.

\begin{tabular}{llcccccc}
\hline \multicolumn{1}{c}{ Seções da Classificação de Patentes } & $\mathbf{2 0 0 0}$ & $\mathbf{2 0 0 1}$ & $\mathbf{2 0 0 2}$ & $\mathbf{2 0 0 3}$ & $\mathbf{2 0 0 4}$ & Total \\
\hline A & Necessidades Humanas & 21 & 26 & 40 & 57 & 68 & 212 \\
B & Operações de Porcessamento; Transporte & 4 & 6 & 12 & 16 & 17 & 55 \\
C & Química e Metalurgia & 39 & 30 & 80 & 70 & 72 & 291 \\
D & Têxteis e Papekl & 2 & 0 & 1 & 2 & 1 & 6 \\
E & Construções Fixas & 0 & 4 & 3 & 4 & 3 & 14 \\
F & Eng. Mecâniuca; lluminação; Aquecimento; Armas & 4 & 1 & 11 & 5 & 9 & 30 \\
G & Física & 9 & 11 & 31 & 40 & 33 & 124 \\
H & Eletricidade & 3 & 6 & 9 & 15 & 10 & 43 \\
\hline
\end{tabular}

Fonte: Inpi (2007, p. 22).

Mesmo que o levantamento do INPI tenha levado em conta cinco anos de depósitos, pode se inferir que existe uma proporcionalidade equilibrada por área, nas chances dos depósitos tornarem-se patentes. Dado que, comparando-se os dois resultados, verifica-se que a quantidade de registros nas áreas é proporcional.

Retornando aos dados das concessões, a subárea que concentrou o maior número de invenções pertence à grande área C. Sendo a C02F 'tratamento de água, de águas residuais, de esgotos ou de lamas e lodos', com 38 patentes.

A explicação deste resultado pode ser traduzida nas palavras de Mayerhoff (2007, p.22), para quem as
[...] tecnologias visando garantir a qualidade da água dos mananciais têm sido alvo de pesquisa e desenvolvimento há várias décadas em todo o mundo. A demanda por novas tecnologias para o tratamento de efluentes industriais e municipais é cada vez maior, diante da crescente conscientização da sociedade com relação aos altos níveis de poluição e à consequente escassez da água do planeta.

Ainda, nota-se que a universidade que obteve o maior número de concessões em uma determinada área foi a UNICAMP, com concentração na área $\mathrm{C}$ e tendo 81 patentes concedidas. A USP também se sobressai com 43 registros na área C. Além disso, as duas instituições mencionadas são as únicas que figuram nas oito grandes classes da CIP com patentes concedidas. 


\section{CONSIDERAÇÕES FINAIS}

Respondendo à pergunta de pesquisa em linhas gerais, as características das patentes concedidas às UPBs pertencem às áreas de Química e Metalurgia, são desenvolvidas por professores com formação em Química ou Engenharia Mecânica e pertencem a UNICAMP.

Identificou-se em algumas áreas da CIP, como área D e E, o baixo volume de registros, o que pode indicar a falta de valorização ou incentivo a cultura de patenteamento nas referidas áreas ou ainda, que são assuntos que não estão no foco das universidades.

Conforme presenciamos na literatura da área, a atividade do patenteamento no Brasil é recente e o governo tem buscado por meio de leis (Lei 10.973 de 2004, Lei 11.196 de 2005 e Lei 13.243 de 2016), incentivar um cenário propicio para as ideias criativas emergirem. Uma das iniciativas mais recentes é o projeto de lei no $772 / 2015$ que busca incluir a disciplina de empreendedorismo no currículo da educação básica e a inovação como finalidade da educação superior.

0 projeto de lei, se aprovado, visa estimular a criatividade e a iniciativa de jovens que podem ou não ingressar no ensino superior. Medidas como esta podem fazer com que as empresas brasileiras (futuramente) passem a competir nos rankings de produção de patentes com universidades e empresas estrangeiras.

Para finalizar, cabe salientar que o país está realizando pesquisas com as solicitações de patentes para identificar a atividade inventiva, já que as concessões são consideradas invenções ultrapassadas. No entanto, possivelmente, como mostram os dados, muitas das invenções não serão protegidas e ficarão à deriva. Caberia em uma próxima pesquisa identificar os possíveis motivos de insucesso, a fim de reparar os gargalos existentes no fluxo de concessão das patentes.

\section{REFERÊNCIAS}

BRASIL. Lei no 9279, de 14 de maio de 1996. Regula direitos e obrigações relativos à propriedade industrial. Planalto. Brasília, DF, Disponível em:

http://www.planalto.gov.br/ccivil 03/leis/19279.htm. Acesso em: 04 jul. 2014.

BRASIL. Ministério das Relações Exteriores. Manual de orientações gerais sobre inovação. Brasília: Ministério das Relações Exteriores, 2011. 186 p. Disponível em: http://redsang.ial.sp.gov.br/site/docs leis/pd/pd9.pdf. Acesso em: 20 nov. 2015.

CASTRO, Biancca Scarpeline de; SOUZA, Gustavo Costa de. 0 papel dos Núcleos de Inovação Tecnológica (NITs) nas universidades brasileiras. LIINC em Revista, v. 8, n. 1, p. 125-140, 2012. Disponível em: http://liinc.revista.ibict.br/index.php/liinc/article/view/465. Acesso em: 8 maio 2016.

DAGNINO, Renato; GOMES, Erasmo. A relação universidade-empresa: comentários sobre um caso atípico. Gestão \& Produção, v. 10, n. 3, p.283-292, 2003. Disponível em: http://www.scielo.br/pdf/gp/v10n3/19163.pdf. Acesso em: 1 abr. 2016.

GUIA DO ESTUDANTE (São Paulo). Profissões. 2015. Disponível em:

http://guiadoestudante.abril.com.br/profissoes. Acesso em: 1 abr. 2016.

IBGE. INSTITUTO BRASILEIRO DE GEOGRAFIA E ESTATÍSTICA. Censo Demográfico 2010. 2010. Disponível em: http://www.ibge.gov.br/home/estatistica/populacao/censo2010/. Acesso em: 13 mar. 2016. 
INPI. INSTITUTO NACIONAL DA PROPRIEDADE INDUSTRIAL. Universidades Brasileiras Utilização do Sistema de Patentes de 2000 a 2004. 2007. 46 p. Disponível em: http://www.propesp.ufpa.br/spi/arquivos/Universidades BrasileirasUtilizacao do Sistema de Patentes de 2000 2004.pdf. Acesso em: 29 abr. 2016.

JUNG, Carlos Fernando. Metodologia Científica e Tecnológica. Campinas: Unicamp, 2009. 58 slides, color. Disponível em: http://www.dsce.fee.unicamp.br/ antenor/mod6.pdf. Acesso em: 27 out. 2015.

MAYERHOFF, Zea Duque Vieira Luna. Inovações estão em aperfeiçoar o tratamento de águas e efluentes. Inovação Uniemp, v. 3, n. 1, p. 22, 2007. Disponível em: http://inovacao.scielo.br/scielo.php?script=sci arttext\&pid=S180823942007000100012\&lng=pt\&nrm=iso. Acesso em: 18 abr. 2016.

OCDE. ORGANIZAÇÃO PARA COOPERAÇÃO E O DESENVOLVIMENTO ECONÔMICO. Manual de Oslo: diretrizes para coleta e interpretação de dados sobre inovação tecnológica. Rio de Janeiro: OCDE, EUROSTAT, FINEP, 2005. 136 p. Disponível em:

http://www.uesc.br/nucleos/nit/manualoslo.pdf. Acesso em: 20 out. 2015.

OLIVEIRA, Rodrigo Maia de. Proteção e comercialização da pesquisa acadêmica no Brasil: motivações e percepções dos inventores. 2011. 167 f. Tese (Doutorado) - Curso de Política Científica e Tecnológica, Instituto de Geociências, Universidade Estadual de Campinas, Campinas, 2011. Disponível em:

http://www.bibliotecadigital.unicamp.br/document/?code=000795973. Acesso em: 10 mar. 2016.

PETROIANU, Andy. Autoria de um trabalho científico. Revista da Associação Médica Brasileira, v. 48, n. 1, p. 60-65, 2002. Disponível em:

http://www.scielo.br/pdf/ramb/v48n1/a31v48n1.pdf. Acesso em: 25 mar. 2016.

SILVA, José Carlos Teixeira da. Tecnologia: conceitos edimensões. In: ENCONTRO NACIONAL DE ENGENHARIA DE PRODUÇÃO, 22., 2002, Curitiba. Anais... . Rio de Janeiro: Enegep, 2002. p. 1 - 8. Disponível em: http://www.abepro.org.br/biblioteca/ENEGEP2002 TR80 0357.pdf. Acesso em: 27 nov. 2015.

VERASZTO, Estéfano Vizconde et al. Tecnologia: buscando uma definição para o conceito. Prisma.com, n. 7, p. 60-85, 2008. Disponível em: http://revistas.ua.pt/index.php/prismacom/article/viewFile/681/pdf. Acesso em: 1 nov. 2015.

WIPO. WORLD INTELLECTUAL PROPERTY ORGANIZATION. Módulo 7: patentes. In: Curso Geral de Propriedade Intelectual à Distância. Switzerland: Wipo/Ompi/Inpi, [2014]. 61 p. 01-61.

Editores do artigo: Adilson Luiz Pinto, Rafaela Paula Schmitz e Enrique Muriel-Torrado 